\title{
Kurt Ludewig
}

\section{Systemic therapy - A practical implementation of systemic thinking}

\section{KEYWORDS}

Systemic therapy, Biological cognition theory, Autopoiesis, Sociological system theory, Mental systems

\begin{abstract}
A summary presentation of the historic development of systemic therapy as the follow-up to family therapies, with the usage of new metatheoretical thinking from the constructivist point of view is followed by a description of the material theoretical conditions of this psychotherapeutic approach, with particular consideration for the theories of cognition and autopoiesis by Chilean biologist Humberto Maturana as well as the sociological system theory according to German sociologist Niklas Luhmann. This is followed by an understanding of interaction systems with respect to the theory of therapy, as developed by the author - the member concept, as well as a system-theoretical adequate conceptualisation of psychical systems. The work ends with a short presentation of the implementation of the described theoretical concepts in systemic therapy practice.
\end{abstract}

Adam Mickiewicz University Press, pp. 177-205

ISSN 2300-0422. DOI 10.14746/kse.2019.15.12

\section{The origins}

A significant number of psychotherapist found in the 1970s much pleasure to strongly introduce the social contexts of their clients in their therapies. The work of the second Palo Alto Working Group headed by Paul Watzlawick (Watzlawick et al. 1967) in particular, concerning the relations between communication theory and psychotherapy reverberated broadly. At that time, I was a student of psychology at the university of Hamburg, and can still remember very well, how a photocopied edition of the German translation of this book was available everywhere as a "pirate copye«. It was talked about and discussed. So-called Watzlawick's Axioms, like "One cannot 
not communicate", were the talk of all students of social sciences such as psychology, sociology and paedagogy. At that time - during the 1960 student revolutions - specifically these sciences were at the centre of fundamental transformations. Hamburg saw institute appointments soon after they began in Berlin, the degradation of the professors and strong struggles towards democratisation and liberalisation of studies as well as of university structures. Specifically in Hamburg, a city traditionally socio-democratic, politics were ready and open to changes. In this historic context a text took centre stage that moved communication in itself into the spotlight, calling for a transformation of thinking that focused on the individual within applied psychology, and found fertile ground. At that time, one learned at very much positivistically arranged psychological institutes exclusively behavioural therapy and, at best, client-centred psychotherapy. The approaches of depth psychology and psychoanalysis that were valid until that time were considered to be pre-scientific and obsolete. Still, these two approaches, considered to be scientifically valid, were neither attractive nor convincing for some of us, and moreover they seemed to strongly limited to individual needs. The new approaches, founded on communication, assumed in turn a change in perspective towards social issues and relations. Entirely in line with our expectations, the expansion of the individual to their social contexts set a real revolution in psychotherapy in motion.

In the 1970s, psychotherapy experienced rapid growth of differentiation. Primarily within the humanist psychotherapies that formed as a result of World War II, many new approaches were established, among them family therapies. In the beginning they were mostly developed by psychoanalysts. These people reached the limits of their methods in particular when therapeutically dealing with psychotic and delinquent youths, and they searched for new ways of access. The most important founders of approaches that aimed at including family members of young patients were, among others, beside the employees of the first Palo Alto group headed by Gregory Bateson (e. g. Bateson et al. 1956, Bateson et al. 1969, Bateson 1972), the groups headed by Lyman Wynne and Margaret Singer in Rochester (e. g. Wynne \& Singer 1965), Salvador Minuchin in Philadelphia (e. g. Minuchin 1974) and Harold Goolishian in Galveston, Texas (conf. MacGregor et al. 1964).

\section{Psychotherap - Revolutions}

\subsection{Family therapies - the first revolution}

Until halfway through the 20th century, psychotherapy was theoretically founded for the most part by way of aid from physics and medicine. It was only in the 1950s 
that proper psychosocial models came to be. The origin of pathological or divergent processes was sought rather in the interpersonal sphere than in the somatic and/ or mental one. The therapist gradually gave up their distanced, analytical attitude and became an actively involved party. In this regard, the observing look turned from the individual to the social network. Family therapy was born; within psychotherapy, that emerged, what Switzerland's Gottlieb Guntern (1980) referred to a bit later as the Copernican Revolution in psychotherapy, namely the move from the psychoanalytical to the systemic paradigm.

First attempts to include family members in children's therapy were supposedly made by Alfred Adler in Vienna in the 1920s (conf. Ackerknecht 1983). An individual practice in family therapy, however, was only established in the beginning of the 1950s in the United States; Europe followed a decade later. In the United States, individual teams began to work with families in therapy, independently of each other. These clinicians asked, how was it possible that youths first suffering from "Schizophrenia" returned to hospitals from their families, frequently with heavy relapses, after achieving improvements by inpatient treatment and being released home. In order to clarify what happened, they invited parents to talk or searched for them. Along the way, they were able to recognise certain regularities in the interaction behaviour of the families, and also concluded that the improved condition of their patient could be stabilised if these patterns were shattered (for a historic reconstruction of these developments conf e. g. Lynn Hoffman 1981).

Theoretically, the superstructure valid until that point, focusing on the individual, was not sufficient to handle the complex events and histories in families. This situation forced a rethinking. The pioneers of family therapy successfully attempted to explain their pragmatically executed practice with their own, temporary concepts. Significant impetus in this regard came from the work of the polymath Gregory Bateson, who just happened to be dealing with issues within psychiatric research in Palo Alto, California. The activity of this first Palo Alto Group brought about in the year 1956 the frequently quoted »double bind hypothesis « (conf. Bateson et al. 1956). It was to become a milestone in the further development of family therapy. Subsequently and gradually, an understanding of psychopathological disturbances through the prism of system theory was able to prevail. Instead of mental components and states, binding patterns and processes moved into the spotlight; properties, constancy and linear causality ceased to be the basic terms; they were replaced by completeness, feedback and circularity.

In the 1970s, family therapy became acknowledged by clinicians and psychotherapists. All leading schools - among them, psychoanalysis, behaviour, Gestalt and client-centric therapy - expanded their offer to include working with families. 
In most cases, however, they only expanded their setting from the individual to the family, not contributing significantly to the further conceptual development of the new approach.

The core of the newly formed family therapy from the United States was initially made up of two approaches: the strategic approach (Haley 1976) and the structural approach (Minuchin 1974). There are many conceptual and methodological similarities between these two approaches. Pragmatically focussing on efficiency, they perceive families as open social systems that may be purposefully changed in terms of structure through interventions. The family forms a network of behaviour rules serving to maintain its inner balance - the family homoeostasis (conf. Jackson 1981). Internal and external threats to homoeostasis are neutralised or dismissed by way of negative feedback - often assessed as symptoms. Symptomatic behaviour also has an important function in terms of family survival, and in this regard is not an expression of individual pathology, but any sort of dysfunction of the system of the family requiring a correction. One can then speak of psychotic or psychosomatic families, and focusing on individuals - symptom carriers or index patients.

Systemic family therapy

Disappointed with the possibilities of psychoanalysis in terms of treatment of anorectic disorders, Milan's psychoanalyst Mara Selvini Palazzoli started halfway through the 1970s to search for something new. After looking for employment with Jay Haley, Paul Watzlawick and Salvador Minuchin in the United States, and encouraged by the cybernetic and epistemological writings of Gregory Bateson, she published in Milan in the year 1975, together with three colleagues - Luigi Boscolo, Gianfranco Cecchin and Giuliana Prata - a book that thoroughly influenced me and many others: "Paradox and Counterparadox" (conf. Selvini Palazzoli et al. 1975). This marks the shift from the then-contemporary family therapies to a new understanding of human problems and their therapeutic treatment: systemic family therapy. It shall be the direct predecessor of proper systemic therapy that was formed in the beginning of the 1980s.

The Milan approach holds the family to be a self-organised system. Pathological families are considered to be victims of an inescapable communicative "game«. In this game, the individual members are forced to enter into paradoxical forms of interaction to protect the homoeostatic regulation of the family system. In order for the therapy to be successful, it must be opposed to the pathogenic game that feels like a paradox - counterparadoxes must be developed. The pathological behaviour is considered to be 'functional' through suitable interventions, provoking 
the family to opposition and to change of the game. The goal of the 'paradoxical' intervention is to block or disable the pathological game of the family with a counterparadox.

\section{Summary}

Family therapy introduced mainly the following important novelties:

- The transfer of circular thinking onto the understanding of human interactions, meaning, a departure from linear-causal patterns of explanation;

- The shift of pathological phenomena from persons to interpersonal processes;

- It was also possible, thanks to orientation based on cybernetic models, to shorten therapeutic processes, to simplify them and make them more efficient.

\subsection{Systemic therapy - The second revolution}

What does "systemic" mean here?

Before I move to a description of this therapeutic approach that developed only in the beginning of the 1980s with breathtaking speed, I want to include a word or two to explain the meaning of 'systemic' here. Differing from somatic medicine, in which systemic medicine and interventions are such that apply to the entire organism, the adjective 'systemic' applies here to a general perspective, to knowledge from systemic theories. I use this term in plural here, because it is used differently by diverse disciplines. »Cybernetics« or »synergetics« in physics, »dissipative structures « in chemistry, "autopoiesis « and »self-organisation « in biology, "self-reference « in sociology and "radical constructivism " in philosophy, they are all variations on one topic and differ primarily in terms of the objectives and the terminology of the original fields. Their common denominator is namely a protective confrontation with complexity, meaning, an attempt to limit as much as possible unavoidable reductionist assumptions. It is their goal, to put it in the words of the German family therapist Helm Stierlin (1983), to provide "complexity-maintaining complexity reduction". Systemic thinking liquefies the analytical discourse of the West and forms a synthesis, within which all significant approaches of natural sciences, humanities and social sciences can find their place. Within this "new synthesis", man functions as the discoverer and protector of their mental worlds (conf. among others Varela et al. 1991; von Foerster and Pörksen 1998).

To put it in short, "systemic" in this regard describes a general thought approach that deals with systems, meaning, with thought structures or relations that 
are generated in order to cognitively arrange human and other phenomena. In this sense, this thought approach sees itself epistemologically as a constructivist one. As will be shown later, this view entered psychotherapy towards the beginning of the 1980s. This caused, among others, a fundamental departure from positivist objectivisms and from approaches based on feasibility/ doability.

The birth of systemic therapy

Not long after the Milan concept of family therapy solidified its presence not only in Europe, but worldwide as well, a young psychologist from Texas held in Autumn of 1981 in Zurich a lecture that was to lead to a radical change in the understanding of therapeutic relations (conf. Dell 1982). This referred in particular to concepts of authors hitherto unknown in the area of therapy, Chilean neurobiologist Humberto Maturana, and Francisco Varela. Using these concepts, Paul Dell was able to sustainably shake up the theoretical foundations on which those of family therapies were built. After the congress in Zurich, we immediately commenced studying and learning these newer thoughts and including them in our understanding of psychotherapy. The goal in this regard was not a minor one. Our purpose was to provide a new metatheoretical ground for psychotherapy. As a result, step by step, a theoretical network was created, in which newer practices of systemically-aligned therapy could be embedded. In our first step, we particularly strongly referred in the years 1981-1984 to biological cognition theory according to Humberto Maturana (conf. e. g. Maturana 1982, Maturana \& Varela 1972, 1984). In the year 1984 we amended our metatheory step by step using concepts from sociological system theory according to Niklas Luhmann (1984). A first summary written work on the concepts created in this way was provided in the year 1992 in the study work "Systemic Therapy" (Ludewig 1992). Below I shall describe the key foundations, on which the new systemic therapy was constructed: The biological and sociological basics. Afterwards I shall provide the psychological foundations.

\section{Systemic thinking - theoretical conditions}

\subsection{Biologische Grundlagen}

The central aspects of the concepts attributable to Maturana are based on his theory of the living, the theory of autopoiesis, developed in cooperation with Francisco Varela. Diverging from the then-contemporary understanding within traditional biology, Maturana does not satisfy himself in his explanation of living processes with listing individual partial aspects (properties) such as the metabolism, move- 
ment, growth, reproduction, etc, he also doesn't refer to vitalistic simplifications. For him, the living being is a system with a specific interconnection of components: the autopoietic organisation. The system lives as long as its autopoietic organisation remains in concert with its environment. The concept of autopoiesis and its implications have in recent decades provided sustainable influence on many disciplines, among them philosophy, jurisprudence, sociology, cybernetics and psychotherapy.

The term "autopoiesis - Gr. autos = self; poiein = design, create, produce was introduced by Humberto Maturana and Francisco Varela in the year 1972 in Chile in their book De máquinas y seres vivos (Machines and living things). In order to be recognised as such, a living thing must fulfil the conditions of an autopoietically organised unit. The dynamics of its states must create both its components as well as its boundaries that provide a limit to this dynamic and which in effect enable it. The dynamic and the limit of such a unit are different in terms of structure and function, however, in the existential sense, they belong to that which constitutes the unit.

The unit of the »cell« fulfils these conditions. Biochemically speaking, it functions like a "molecule factory « that continually produces its own constituent components: molecules. In course of this, not only are the basic building blocks of the "factory« formed, but also those components that delineate it topologically (cell wall or membranes). If the network is broken, interrupted or damaged in important places, the production of components ends and the autopoietic organisation falls apart.

The concept of autopoiesis has significant consequences for the understanding of living beings not only as individuals, but also as beings that are socially embedded, hence, also in terms of therapeutic phenomena. It follows from the concept of autopoiesis that biological systems as living beings have a predetermined structure, are autonomous, operationally closed, lacking purpose and atemporal (conf. e. g. Maturana 1982). The autopoietic organisation is principally invariant, hence, it remains constant as long as the being lives. The structural composition may vary to the extent that organisation remains constant. The relevant current condition of its structure determines the limits, within which a living being is able to change without losing its autopoietic organisation, meaning, without dying. On the basis of its structure, the living being is able to select the type and mode of the environmental events that are able to cause changes within it. External influences may irritate (perturb, violate) the structure of the being only to the extent that this structure allows. It is not these influences that determine the effect, but the current structural condition of the biological system. In this regard, Maturana speaks of living systems as having a predetermined structure. Living beings live only as long 
as they are able to generate and maintain themselves, meaning: their constituent components. Their mode of work determines hence their entire phenomenology. Accordingly, they also basically self-regulate, meaning, they are autonomous, and, differing from non-living systems, identical with their products (conf. among others Varela 1979). Autonomy refers here to entelechy, a sort of completeness, perseverance, hence neither autarchy nor socio-political self-determination.

Furthermore, it follows that living beings are basically not »instructable« (structurable), but in any case "unsettlable« (or irritable, perturbable, interferable). As they do not function on the basis of »input « and "output «, they cannot be determined heteronomically. They can only be influenced if the characteristics of a being (or its species) and its environment is sufficiently well known that changes of specific environmental conditions are able to »trigger « required behaviour of/ in the living being. In this regard, the change is not brought about causally, but only »incited «. Only in this sense one may speak of a causality of actions. Otherwise the postulation of linear causality in this regard is misleading. This indicates the central challenge of a systemically conceived clinical theory: It must forgo assumptions of causality and still develop pragmatically usable concepts.

A network organised autopoietically is only able to operate using its own states or conditions. It works by self-reference by recursively regulating its own states, in order to protect its organisation. Living beings are thus operationally closed; their operations may only be based on their earlier states, and not on external conditions. And because an observer is able to utilise their outside perspective in order to consider the living being and its environment as a whole, they perceive an energy and material exchange between the organism and its environment. This, however, says nothing about the mode of operation of the organism and does not substantiate any abstract, causal conclusions. The outside world is relevant for a living being only in the sense that it uses the same due to its structure, in order to be able to continue.

Similarly, the nervous system operates as operationally closed, and this determines the mode of action of cognition. Nerve cells form an operationally closed network and may only react to external events if they are excited according to their structure. "Excited « receptor cells »discharge« in a uniform way, irrespective of what caused this discharge of theirs. As the components of the nervous system operate only with own states (or the relations between them), they are unable to differentiate between internal and external triggers. There would be no neurophysiological mechanism that could enable or permit an explanation of any sort of cognitive difference between illusion and perception (cognition induced internally and externally). This differentiation that is so important in human life refers to the 
activity of mental and social processes, for instance, in the form of descriptions and explanations.

Finally, there follows from the concept of autopoiesis that living systems neither follow objectives or goals nor fulfil programmes or functions. Criteria are applied by external observers when they observe living beings in a broader context and are searching for an orientation that could provide a meaning. The concepts of objective, goal or time thus serve a sort of coherent description, however, they do not describe the internal functioning of living beings.

\section{Cognition}

Maturana's contribution to the understanding of the process of perception, or of cognition, can be summarised by the following theses:

- Human cognition is determined, as a biological phenomenon, by the structure of the organism and not by objects from the outside world.

- Humans have an operationally and functionally closed nervous system that does not differentiate between internal and external triggers; hence, perception and illusion, internal and external stimuli principally can not be differentiated between.

- Human cognition results from "private« experiences; as a capacity of the organism, it is basically bound to the subject and thus non-transferable.

Concerning the question as to how one can achieve knowledge or cognition, there follows:

- Cognition/ knowledge is neither a true representation of a reality separate from the one performing the cognitive process, nor a random or arbitrary structure. It rather serves to uphold life, thus corresponding to the structural capacities and the status of the cognitive entity.

- The traditional requirement of objectivity as the correspondence of the external and the internal (adaequatio rei et intellectus) exceeds human cognitive capacity. The biological bond of all cognition and the lack of any sort of mechanism to differentiate between illusion and perception limits the criterion of objectivity to purely communicative objectives.

- The content of communicated knowledge is aligned with the biological structure of the recipient. Communication is an ongoing process that must be renewed, the efficiency and information content of which is determined solely by the addressee. Any sort of equivalence of structural conditions of the »sender « and »recipient « can neither be purposefully achieved nor determined by an observer. Hence, it is forgone as a criterion of scientific perception or truth. To illustrate this situation, Maturana stated: "In a curious 
way, I am entirely unaccountable for what you are hearing, but fully responsible for what I am saying" (Maturana 1990, p. 63, transl. from Spanish by the original author of this article [transl. into English by the translator of the article]).

The usage of cognition. Would one still want to limit arbitrariness and lack of transparency in scientific discourse, then only one pragmatic criterion can be considered: The criterion of communicative usability. This criterion as proposed by me (conf. Ludewig 1988) expands upon the concept of viability of Ernst von Glaserfeld (1987). It is fulfilled, if the speaker and addressee are able to optimally coordinate their purposeful procedure by way of an exchange. A piece of knowledge is useful communicatively if it can be described, meaning: conveyed, if it promotes the coordination it struggles for and if describes an advantage (gain) as compared to other pieces of knowledge or the lack thereof.

A challenge. Systemic thinking takes hope of being able to discover away from the scientist if they only adhere to the rules of the game. The scientific project of eliciting from »the world « its truths, loses its meaning; at the same time, research without care for the effects becomes anachronistic and irresponsible. Just like any sort of criticism against traditional obvious factors and any new sense or meaning, systemic thinking also comes with two consequences: It opens up for the scientist unexpected perspectives an at the same time robs them of the certainty of the known. The way towards anything new first leads through uncertainty, doubt and rejection. This describes the present-day position of systemic thinkers: Not only do they have to check whether the known tools of science are also useful in the new system of thinking, but at the same time they have to develop relevant criteria and redefine their position.

Description. Any type of describing constitutes the result of an operation of differentiation using language (conf. Maturana 1982). Describing is composed of differentiating, meaning, it assumes a comparison in the cognitive area of the observer, between units brought about through cognition - be it between objects, between an object and a background, or between an object and a non-object. When describing, the observer generates differences in their own way: linguistically. The basic components of the human world are, hence, descriptions: Anything that is not described, that is not differentiated by language, is missing from it. Any attempt to leave the sphere of that which is described, and to reach "the things themselves «, concludes with a further description - it is, hence, pointless: One always remains in the sphere of the described. This applies in particular to describing people. In this regard, comparative observation may be based on various phases of life (biographically), on other people (differential) or abstract, general values 
(normative). In any case, comparisons are always necessary, as no description can emerge without them.

As they are formed in the cognitive area of an observer, all descriptions point to their creator. After all, behind every description stands an observer. To describe is self-referential (it refers back to oneself), it takes place in a closed field of recursive, retroactive operations. Human discovery is hence based on an endless retroactive process of internal »calculation « of the own states of that which is being discovered, which constitutes the cognitive area (conf. von Foerster 1985).

The relation between I and You. Human cognition is based on observation accessible only as/ when described. As observing and describing always takes place in the closed cognitive area of an observer, people generate their cognitive realities basically in loneliness. Still, all descriptions stem from the fact that man, as a linguistic being, is a communicating one, and this requires the existence of a different being that is also able to describe. Man is thus at the same time alone as caught in their biological structure and »connected « or "coordinated» with others. This substantiates the dual identity of man as being both biologically individual and linguistically social. In order to understand discovery of knowledge, we must hence also not only follow the operations of the observer, but also that communicative process that enables and maintains human cognition.

As lonely creator of their realities, man has access neither to an independent object world nor to the psyche of others. Still, it can perceive (and describe) themselves as a communicative being, and discover that there are other people, in structural terms - equal to them, with whom they may communicate. They may thus conclude both on the singularity/ individuality of their existence - their I-Being - as well as on the existence of an independent You. The relation between I and You substantiates the area of joint eperience, from which the social [sphere] arises. Considered against this backdrop, man lives in the equation Reality $=$ Community (von Foerster 1985, p. 41).

As every discovery is based on differentiating, no I may arise without assuming an independent yet structurally strongly related You. Even if this assumption is only "arrived at « cognitively, it still assumes communication and itself enables communication. Men are basically unfathomable for one another, still, they may ascribe to themselves structural equality and, in this manner, pragmatically overcome the existing chasm. Communication may thus be considered to be "cooperative problem-solving «, through the aid of which people conquer their mutual opacity.

Within a "We" - the social system - there arises the humanly specific relation between the biological individuality and the social-communicative identity. In this 
I recognise the "systemic principle", on which all that follows is based, particularly as it is founded on systemic thinking.

Existence. Linguistic differentiation brings about units, of which the objects of our material and mental world are composed. The question as to whether something »exists « basically aims at the operation that must be performed in order to bring the relevant unit into the area of experience of the questioning. It asks of the "recipe« with actions (differentiations), on the basis of which the described experience could be reproduced. Still, the reproduced may never have exactly the same structure as the original experience, as it stems from a different area of experience. All consensual expressions of existence - even scientific ones - are based on the operational reproduction of experiences. Even if in course of this it is always the questioning party that determines the validity of the achieved »recipes", they usually rely on criteria of their linguistically-consensual community (family, tribe, society or »scientist community«). Knowledge arises by communication by way of adhering to valid criteria of understanding (or of communicative usability).

The human [factor]

People produce their own specific area of existence, namely, one of "existing in language". In operational terms, interaction takes place when individuals meet and "perturb" each other or trigger structural changes. By repetition, gradually, a structural connection is established. Consensus, or an area of sensual coordination, is established by recurring interaction. All living beings are ale to coordinate their behaviour in some measure with that of others; this is when that takes place, what Maturana referred to as "primary behaviour coordination". Man is, additionally, able to generate areas of second-order behaviour coordination. This specifically human phenomenon was designated by Maturana in Spanish with the neologism "lenguajear", translated into English as "to language", which I refer to in German as "Linguieren". These terms refer to the fact that the case does not concern use of language but a form of behaviour that takes place when primary behaviour coordinations are coordinated by different forms of behaviour coordination, when people, by way of gestures or noises, refer to primary behaviour coordination. To use an example: If one were to indicate, by a hand gesture, to another that they should open a door that is closed, so that both could pass. In this case, the coordination "pass through the door" is coordinated superordinately by the hand gesture ("to language"). It is irrelevant whether words are used or not. Languaging is more basic than speaking (conf. Maturana 1976).

As a self-referential system, language can only refer back to language. In this regard, "languaging" constitutes a recursively closed, inescapable area that one 
can only be left through being silent, with this silence not being part of human communication. The "objects " of our world and we ourselves as observers, arise in course of instances of linguistic coordination. For instance, the word "table" refers only to the linguistic differentiation of the table, as the described objects have nothing tabley in them. Compared to behaviour coordination in the area of specific activities, the linguistic potential of differentiation is basically unlimited, as that coordination may be described in a broad number of ways. Languaging thus forms the basis of the human mode of living, and forms an independent phenomenal domain. Hence, Marurana's saying: »Everything said is said by an observer to an observer who could be themselves" (Maturana 1982, p. 240 [English version: Maturana and Varela, 1980, p. 8]) thus defines the human area of existence as one of linguistic togetherness.

Explaining. Explaining, the way Maturana describes it, is reforming an experienced situation using components from other situations from life practice. The validity of an explanation is determined by the structure of the one posing the question. In the process of explaining, Maturana differentiates between two options, namely, according to whether this process is considered independently or dependently on the biology of the observer. In the first case, an universal ontological reality is assumed that should in some way be accessible to people, whereby the result must satisfy the criterion of objectivity. In the latter case, the assumption is made that man has no access to any sort of subject-independent reality, and that everything that is real refers back to and relies on observation. Accordingly, there are as many realities as there are applied methods, meaning there is no uni-verse, but there are multiverses. Matuarana suggests to bracket [off] the criterion of objectivity in order to make it clear that the case concerns constituted circumstances. The bracketing should be a reminder that $<$ realities $>$, as binding and as inevitable as they may seem, are always the product of our observation. However, when knowledge or discovery take place and are accepted as useful, for all practical purposes they take on the character of the real (conf. e. g. Ludewig 2013, chapter 3).

However, if one would want to keep the logic of describing as unequivocal as possible, it is suggested to maintain correct logical bookkeeping, meaning, a precise correspondence of terms between the generated phenomenon and the relevant described phenomenal domain. It protects against incoherence and unsuitability (conf. Maturana \& Varela 1984). Correct logical bookkeeping proves to be particularly necessary in the clinical area for the purpose of diagnosis, prognosis and evaluation. This protects from common mixing of phenomenal domains such as, for instance, in course of unilateral descriptions of life problems in analogy to bodily illnesses or as a result of ambient conditions. 


\subsection{Sociological foundations}

The biologically founded concepts introduced by Humberto Maturana reveal themselves as being extremely useful and liberating for psychotherapy, especially with respect to cognitive and linguistic processes. One is liberated from the overly narrow orientation on physical analogies, and, additionally, from holding on to "ontological truths". However, when handling communication and social systems, they reach the limits of the biological, especially since Maturana treats everything that is social basically as a biological phenomenon. The fundamental work "Social Systems " published in the year 1984 by the German sociologist Niklas Luhmann provided us with a phenomenologically sound amendment to the biological concepts of Maturana. Luhmann's systemic theory of the social justifies a phenomenal domain that permits the consideration of psychotherapeutic processes as genuinely socio-communicative occurrences extending beyond the biological.

The concept of the system

The ancient Greek roots of this term indicate those two aspects that describe systems: systema $=$ entity, composed of $s y n=$ together, and histanai $=$ establish (according to Wahrig 1997). A syste is also a complex, meaning: a composite entity that can be delineated from others. There are no systems in themselves, they are relations of order or entities of human observation. According to Luhmann, a precise definition of the concept of the system would require consideration of three differentiation: the system boundary differentiates the entity from a background (difference system/ environment), the components constituting the system (system differentiation) and the relations between the components that hold the system together (difference component/ relation). All these aspects emerge and pass as the system emerges and passes. Components in themselves emerge on the basis of the type of their relations that in turn enable the system being as opposed to its environment. A precise definition of the system thus requires the definition of its constitutive units: Components, relations and boundaries. All of these are constituted by the unit of difference.

Complexity. Systems are complex units that reduce complexity. Formation of systems does not entail increasing complexity or fusing that which already is, but creating another complexity. Complexity is a quantitative term. An amount is complex when its components can not be joined at any given time. The environment of a system arises as a result of system formation and must be more complicated than the one of the system. Without this difference in complexity, the difference between the system and its environment would be void and the system would not 
be recognisable. System boundaries are functional; they separate and fuse the system with its environment. Systems always interact only through their components and not as entireties. The processing of interactions is determined by the internal operationality of the system and not by external influences.

\section{Social systems}

Considering the establishment of systemic theory in the area of psychotherapy, the following shall describe aspects of the social system theory of Luhmann (1984, 1997) that seem relevant to me. Social systems are not composed of mental systems or entire people, but of communication instances and the relevant formation of connections along a mental boundary. To determine a social system, Luhmann suggests to consider communication instances as components of a social system. The relations between these components constitute the establishment of connections between the instances of communication. The system boundary is defined as a mental boundary. For his system theory, Luhmann takes over Maturana's concept of autopoiesis, whereby this concept is not only applied to biological systems, but is also extended to encompass mental and social systems. Such systems constitute themselves by way of establishing differences, and thus may be considered to be autopoietic. The described system types, however, differ according to the fundamental operation of their autopoiesis: Biological systems process and reproduce events at the molecular level, whereby mental and social systems in turn process the sense, or meaning, be it as consciousness or communication.

Luhmann could describe social systems as autopoietic when he considered them to be composed of related mutual communication instances. If social systems were to be composed of people, as Maturana considers it, then they could not be considered to be autopoietic, because social systems do not generate people; communication in turn generates communication. Instances of communication align along a meaning and in this sense generate the system boundary that differentiates between a meaning (system) and a meaning (environment). The physical, biological and mental systems necessary to cause and maintain communication are assigned to their environment. Despite being necessary, they belong to other phenomenal domains and thus are not part of the definition of the social system.

Meaning/ sense and its boundary. Sense, as a specific strategy of selective behaviour under the condition of high complexity, encompasses everything that "has sense" or "makes sense", it is thus a formal concept without differences that cannot be perverted to its opposition or negated. Sense is self-referential; it always and only refers back to sense: "Systems bound to meaning can therefore never experience or act in a manner that is free from meaning." (Luhmann 1995, p. 62). Abbreviat- 
ed to a short form: One cannot not make sense. The selection of a specific usage of sense neutralises temporarily or negates other possibilities, however, without the possibility of eradicating them entirely (Luhmann 1971, p. 12). "Information " causes in the addressee system conditions (without defining them). On the basis of operational closedness of systems, information does not form a specific input; it can only then cause specific system conditions in an addressee, if it finds structures suitable for this purpose. Information aims at causing specific system conditions in the addressee, however, the choice of what is considered information is made by the system itself. Information is experienced as an action, if it is parsed as the system's own performance; else it is deemed to be an external selection, is causally assigned to the external world and is interpreted as an experience. This differentiation gives rise to the difference between the internal and the external.

During processing sense/ meaning, mental and social systems provide for complexity reduction. Sense brings about establishment of connections and continuity as well. At the same time, as a temporary event that must be continuously regenerated, it is basically unstable. Every sense or meaning may be different in the next moment. This aspect is exceedingly significant for the establishment of theory in the psychotherapeutic area, both in terms of understanding human problems as well as of overcoming them.

Double contingency. All communication is characterised by mutual indeterminableness and opacity. Self-referential, meaning, operationally closed systems, do not have any access to their environment or to other systems. Even very precise observation is not able to fully encompass the entire operationality of the other. If this were to happen, both systems would intertwine. Systems with meaning are exposed to contingency, meaning, they can always be different. Communication must also overcome the problem that arises due to the mutual opacity of the participants. Luhmann speaks in this regard of the double contingency and refers in this regard to the fact that people must endlessly be able to handle the problem of both participants being able to do or understand this or that. Because both partners of a social interaction experience at any time double contingency, and both know it. Hence, in order to be able to refer to the actions of another, considering uncertainty, one must take risks, as lack of clarity incites clarification. According to Luhmann, social systems may only emerge because a diffuse initial state would force the creation of structures. Every action works selectively, reduces complexity and thus enables continuity. "Pure" double contingency is not found in any society, as communication is based on societally transferred symbols and expectations. Hence, within the context of double contingency, expectations acquire, a structural value for the production of emergent systems (Luhmann 1984, p. 158). 
Double contingency works autocatalytically in social systems: It facilitates communication without being used itself. Within double contingency, one feels both secure and insecure at the same time. Even if one does not know what the other will do, however, they may trust that they experience the simulation just as one does themselves. Who would take the risk and determine themselves, lets others establish a connection, and is able to refer to it then. Hence, improbability, uncertainty and indetermination always cause the emergence of their opposites. The problem of double contingency bears within itself a solution. Risks are overcome by risky offers. In this regard, there is no alternative to trust. Anybody that would seek to avoid any sort of risk due to distrust, cannot survive.

\section{Communication theory}

Communication is based on actions. The differentiation between action and communication makes the mixing of these concepts possible. Action is assigned to a single actor, communication - wholly in the sense of this term, Lat. communicare = perform together, unify (Wahrig 1997) - requires at least two communicating entities: A sender and a recipient. Accordingly, Watzlawick's Axiom that "One cannot not communicate" can be replaced by an amended formula that "One cannot not make sense". A motion of the hand can be "understood" as a pure movement (action) or for instance as a wave. This depends solely on the current structure of the "Recipient".

According to Luhmann, communication must be considered as a three-part selection process. On the part of the sender, an information is selected along with a mode of communication behaviour, whereby the recipient performs the third selection: Understanding. It results from the difference between information and message. Understanding in this sense does not mean as usual an adequate interpretation of a message, but solely the fact that an observed action is is considered a message, and not just information. If the recipient would understand the action of the sender as a message, then it is irrelevant whether this was intended as such. As this process is respectively borne by operationally closed systems, misunderstandings, lies and dishonesty genuinely form a part of communication and need not be evaluated as pure errors.

Communication process. Separate communication units, for instance, in the form of commands, short greetings when passing or calls for help are usually the exception to the rule. Communication processes in turn fuse many communicative events into a sequence. Communication similarly causes redundancy and difference, not only consensus, as this would result in trivialisation. Redundancy brings about structures; difference opens up further areas for negation, protest 
and opposition. Thus, the social system - just like the nervous system - remains in a form of self-generated permanent excitation that can also be co-determined by the environment.

The member concept

Niklas Luhmann (1984) differentiates between four system types with respect to their base operation types: Machines, organisms, social and mental systems. Therapeutic processes take place as face-to-face meetings on the interaction level, meaning, as a social system concerning primarily the participants. The concepts of the sociologist Luhmann with respect to system theory are particularly suitable to understand macrosocial relations. Hence, it seemed important to me to conceptionally redetermine the dynamics of interaction systems with a focus on psychotherapy (conf. Ludewig 1992). The task was to avoid the dilemma of having to apply clinical theory either only with respect to communication or to people. For this purpose, the concept should be expanded so as to include both the corporeal and the mental in course of instances of communication. The sought concept should be clear enough in order to be able to describe the practice, yet at the same time sufficiently empty and abstract so as to be able to avoid objectification. In order to establish a conceptional bridge between man and communication, I have introduced the concept of the »member « and redefined the components of interactional social systems as «members«.

A member is an abstract working term. It stands for a socially constituted, functional operator that characterises and solidifies a communication process. Members emerge from the communication and undergo constant changes. They exist only as long as the process begins that caused their emergence. Members constitute each other in the communication as "operational coherences«. They emerge only through the execution of communication and are thus qualified as such. An observer who cannot observe communication directly anyway can, however, extrapolate about it by retracing the communicative operations. Members process differences. Members are selecting operational coherences (relations, networks) that enable human communication. They form the functional »link « of the people participating in the communication. Analogously to computer languages, one can compare the relation between man and member with the relation between hardware and the individual calculation processes. This analogy naturally applies only conditionally, as members act recursively and change themselves continuously, so that in most cases they are not executing a fixed programme (»role«).

Man and the member are structurally connected to each other, however, they do not cause each other. Ritualized membership for instance does not assume any 
conscience, however, only as long as this person ponders it. Man and member belong to different phenomenal domains: the biological and the social one. Man in themselves is never a member of a social system, they may only »embody « memberships, meaning, make available the necessary structures of the physical and mental type, to which the member can refer in order to establish communication and enable the construction of social systems. The differentiation between man, member and role proves to be useful for clinical theory. While "man« describes a living being, the social operator "member indicates a single communicative action, and the "role« is a generalised programme to execute a class of memberships (a policeman, a housewife). During therapy, people embody respectfully the participating members in the diverse roles as the therapist and the client/ patient.

\subsection{Psychological foundations}

As the successor to family therapy, systemic therapy was initially interested mainly in social systems. It became gradually clear, however, that this form of therapy is suitable for work with individuals as well. It thus became necessary to adapt the theory to this state of affairs and to expand around it the conceptualisation of mental systems within systemic theory. I have been working on this issue since the end of the 1980s and with time I was able to show such a theoretical concept (conf. Ludewig 2011, 2013). I always use the concept of »mental systems « in plural, particularly as a singular mental system is a synthetic concept without relevance for clinical theory. Mental systems accordingly provide processes that take place in individuals and thus create sense and reproduce. They are composed of emotional-cognitive coherences, that similarly emerge and vanish along with the emergence and vanishing of a specific sense/ meaning. As processes, they are naturally transient and must be permanently regenerated to be able to continue. The psyche as a structural term in turn offers at best a synthesis of many diverse mental systems that take place within an individual at a specific point in time.

Mental systems constitute the individual counterpart to members within interactional systems. The mental and social systems stand with respect to each other in a relation of structural coupling. Even if both system types utilise sense and require each other to be able to exist, they operate, however, separately of each other and always generate in this regard diverse phenomena, here - awareness, there - communication. This relation differs from the traditional concepts aimed at unity, such as personality, identity and the self. These consistently intended concepts of academic psychology were developed within the frmework of analytical and structural thinking. Such concepts only seem useful for a process-oriented understanding of psychology if they are treated as synthetic structures. They simplify 
communication about human conditions. The concept suggested here of psychic systems as transitional processes or events aligns broadly with new knowledge of cognitive sciences. It is there that everything that is mental is more or less connected, understood as mutually dependent processes (conf. e. g. Varela et al. 1992, Roth 2001, LeDoux 2002).

\section{Polyphrenia}

As an alternative to the unity of the mental, the following shall substitute substantial concepts by temporalised ones, unified concepts by differential ones. The avoidance of comparative, objectifying metaphors that have become obsolete and invalid as an apparatus, structure, whole or parts need not necessarily mean that structural aspects must be forgone entirely. Mental phenomena considered to be processes cannot be observed, but may only at best be reconstructed with the aid of observation of actions or thanks to introspection. The identity - the characteristic of man - is considered to be a narrative that is synthesised on the basis of repeated behaviour observations. The description of an identity thus contains a current selective reconstruction from the multitude of the own states that it experiences and the embodied memberships in social systems. This applies both to a self-description as well as to describing others. The questions on the identity of an individual, »Who am I? Who are You? « are posed within the scope of introspective musings or during communication. To the extent that this would require more suitable differentiations, self-descriptions are relational descriptions that may be construed as relational coherences or relational identities, or relational selves.

Mental systems are interpreted here as temporalised emotional-cognitive coherences that always react anew to internal or social demands with respect to a specific sense/ meaning. The components of mental systems - emotional-cognitive units constitute intramental, meaningful processes that can relate to further experiences with the same content of meaning, ensuring this way the continuity of the experience of sense. They are composed of relational components - emotional-cognitive units - along a sense boundary. Mental skills that are already present (thinking, feeling, remembering, motives, etc.) as well as those that are currently being established anew, are mobilised selectively and bound into a relevantly unique relation, an emotional-cognitive coherence. In this way, there emerges in every individual situation an actual $I$, which only exists so long as it is continued by way of connections to further emotional-cognitive coherences. From this perspective, when describing mentality, I assume polyphrenia. With this I describe the broad potential of an individual to generate individual mental systems suitably to the context or to relate accordingly to their past emotional and cognitive experiences. 
Polyphrenia in this regard describes an ability and no array of existing components. In course of communicative and/ or introspective activities, the polyphrenic potential of an individual becomes active; the reaction to this is the formation of a mental system. The current mental systems selectively »take « from the available mental potential and bind individual components of it into emotional-cognitive coherences, into mental systems. A flexible polyphrenic potential could guarantee that an individual would be able to maintain a healthy attitude towards the requirements of their changing environments. Polyphrenia allows flexible adaptation, while a limited state reaching all the way to monophrenia is a significant sign of a reduced ability to adequately react to the multitude of requirements of everyday life.

I assume that a person embodies at any time only one mental system. The continuity in self-experience, meaning, the feeling of permanent identity, is constituted each time by an ad hoc emerging mental system. It is then made available to the person in order to be able to reply to relevant questions in course of self-reflection or as a member of an interaction by way of the description of a personal I. The personal description of a person would certainly include those traits that characterise the self-experience of that individual regardless of whether they are innate or learned and characterise them both for themselves as well as for others. The differentiation between the actual and the personal I corresponds to the difference between a process and a structure, or the temporary and the persistent.

\section{Clinical theory of systemic therapy}

The following, closing section deals with a description of a systemically founded theory of psychotherapy limited to the most important components. Exhaustive presentations can be found, among others, in Ludewig $(1992,2005,2013)$.

Definition. Systemic therapy perceives itself as a contribution to the establishment of a suitable framework for self-change of the individual seeking help. It facilitates trust by way of a stable therapeutic relationship and encourages changing of preferences. It does not perceive itself as causal changing.

Subject. I understand the subject of a systemically founded clinical theory to be a series of diverse social systems with diverse, discernible communications (conf. Ludewig 1992). This allows for the description of the processes involved in the therapeutic situation - the problem, the intervention and the evaluation - to be perceived as a sequence of discernible interaction systems, and not as a profess of a structural whole. These interaction systems are usually: 1) a problem system, 
2) a help-seeking system, 3) an unspecific help system and 4) a specific help system, e. g. a therapy system (conf. Ludewig 1992).

Individual and interactional problems. The formulation of a systemic clinical theory assumes that one first identifies those specific situations that motivate an individual to seek therapy. Such situations are traditionally described as "problems «. Family therapy as the predecessor of systemic therapy holds on to tradition and satisfies itself with defining problems as structural conflicts or deficits, as dysfunctional patterns or communicative disorders of a social system, in most cases, of a family. Harry Goolishian, one of the most innovative pioneers of systemic therapy, formulated halfway through the 1980s a new genuinely systemic concept: the concept of the problem-determined-system (Anderson, Goolishian et al. 1986). This inverted the traditional concept, as it is not social systems that have problems, bt it's problems that generate social systems.

This idea had a revolutionary influence on clinical theory. Well thought-out, this concept came in order to entirely replace the traditional interpretations of psychopathology. One could think about clinically relevant problems without relying on semantics metaphorically derived from medicine or natural sciences, especially as they lead one to use inappropriate concepts such as mental illness and mental disorder. Goolishian's concept focuses on communication and social systems.

Enriched with the emotional processes that inevitably come up in every therapy, and using the constituent components from the communication theory of Luhmann, Goolishian's concept was set upon a materially more comprehensive theoretical foundation: the problem system. In the sense of this innovative concept, the clinically relevant human problems could be considered to be results of failed attempts to conquer an irritation (perturbation, disturbance, interference) that is alarming and that causes suffering. This irritation exceeds - as stress the capacity of a system to overcome it, so that it neither can react adequately nor retreat. As a result, a personal "problem « may arise, which, depending on its intensity, remains an individual $\gg$ ife problem « or becomes a communicative "problem system " (conf. Ludewig 1992). A characteristic trait of human problems, life problems or problem systems, is their stability over time. Problems must be permanently reproduced in order to continue. This applies irrespective of whether the case would concern a single interior monologue or a ritualised communicative pattern, as they are composed of an endless repetition of the same (more-of-the-same). Alternative thoughts and/ or communications that eventually broaden the horizon thus attracting attention away from the problem or able to entirely replace it, have almost no chance at succeeding. The thoughts 
or communications maintaining the problem are gradually reduced to a pattern of permanently self-reproducing repetitions. The participating persons may be aware of this stagnation and suffer from it, but paradoxically may rely on the fact that as long as it remains it will at least not become worse. The relationship between the life problem and the problem system lies, from my point of view, at the core of clinical reflection and thus contains a central main difference for clinical theory.

The therapeutic process

The tasks of the therapist. A methodology of psychotherapy must refer to actions that are suitable tu oppose the dynamics that maintain the problem at hand. In the field of systemic therapy, this goal is approached from diverse perspectives. These range from direct orientation on the problem all the way to an exclusive solution orientation. In agreement with the basic assumptions represented here, this goal is approached by way of a combination of aspects of communication theory of Luhmann with interpretations from emotion theory (conf. e. g. Maturana 1988; Ciompi 1997). This combination contains the necessary components to describe a therapeutic change as the dissolution of life problems and/ or problem systems.

I understand life problems and problem systems to be repetitive thought and behaviour patterns that maintain a status quo that is usually perceived as being uncomfortable because no possibility is seen to precisely determine the effects of a change ahead of time. It is not clear whether the next step would have the effect of reducing the burden or on the other hand, make the situation worse, with an increased volume of suffering. In these conditions, no change seems more certain than any venture of a change. This explains why people, despite all the discomfort, remain enveloped in the continuing repetition of a specific pattern. With respect to the therapeutic strategy it proves to be essential to strive to break the pattern of repetition (conf. Watzlawick et al. 1974). This would be simple if the participants would suit and not be held back by the fear of making the situation worse. The therapist is thus required to establish for the client framework conditions that would offer encouragement and security, that would make it easier for them to take on the necessary risks and to try out uncertain changes. The therapist must be able to maintain for this purpose to a certain extent an "artistic balance between the empathic value judgement of the client and their right to be what they are on the one hand, and on the other hand downplaying the problem and the behaviour patterns that maintain it as a balance between a suitable appreciation of the client and the therapeutic encouragement to change (inter- 
vention). In other words, this balancing may provide the client with stabilising emotional security that makes more probable the necessary destabilisation of the problem. The clients are thus encouraged to undertake a "change of preferences «, meaning, to shift their sights from the problem to possible alternatives and other resources that are suitable to replace the problem. In this respect, systemic therapy generally may be perceived as a social activity that is aimed at establishing more advantageous framework conditions for the self-modification of the client - help towards self-help.

The therapist's dilemma. According to the theory-based abandonment of lineal causality, the therapist is confronted with the following dilemma: "Act effective$l y$, not knowing ahead of time, how and what your actions would cause! (conf. Ludewig 1992). Any therapist taking this dilemma seriously would reject both their own determination of therapeutic objectives as well as any causal process or procedure planned ahead of time. They shall rather attempt to encourage the client to formulate their own wishes and concerns or desires in such a way, on the basis of which the agreement may be established on the therapeutic task, which then would introduce the therapeutic activity. The therapist is mainly obliged to describe a suitable context for helpful therapeutic discussions. The knowledge that the assumption of simple linear causality in the interpersonal domain is misguided with respect to theory was one of the most significant contributions of systemic thinking to psychotherapy.

Systemically speaking, every mention of the problem brings with itself the danger of confirming the stability that is uncalled for, especially, as Steve de Shazer (e. g. 1988) demonstrated, that the construction of a "solution " need not necessarily align itself with the structure of the problem. In this regard, the countering or solution of a problem requires no fundamental knowledge of the same. While certain clients profit from direct orientation on solutions, others think it better to be able to speak about their problems and be listened to. As the effect of such measures cannot be estimated ahead of time, the therapist should be open for the relevant requirement of the client and, according to the situation either permit "problem talk« or work with "solution talk«, not forgetting that therapy is, after all, about striving for change.

The dilemma of diagnostics. The nest challenge to be overcome with respect to the formulation of clinical theory from the systemic perspective results from diagnostics. Aiming at maintaining complexity and variability, meaning, focusing on not to easily fall prey to simplifying reductionism, the systemic therapist must try to maintain also in this regard the difficult balance between reductionist and systemic requirements. A way out of the dilemma of diagnostics is indicated by the 
concept of "survival diagnostics" (Ludewig 1999). This concept calls for therapists to take on that attitude of interest or curiosity, in the sense of Cecchin (1987), towards all such aspects from the life of the client that have made it possible for them to survive until the present. Such an attitude allows one to search for resources, alternatives, exceptions and whatever else may be useful in order to shift the attention of the client from the problem and to open it to alternatives. With this attitude as a leading orientation it is then possible to view the client as an expert in themselves, without devaluing or ignoring the expertise of the clinician.

The intervention. Since it was created about 30 years ago, systemic therapy had only developed very few special techniques. It utilised the majority of its work to formulate a therapeutic attitude that could be reconciled with systemic thinking, and less on developing new techniques. The rather limited special range of methods in systemic therapy, however, does not constitute an insurmountable problem, especially since there is no theoretical or practical necessity to reduce systemic practice to any sort of specific technology. A possibility of finding whether a specific technique is suitable or not is the adherence to the following criteria: Advantage with respect to therapy objectives, beauty with respect to the selection of interventions and respect with respect to the interpersonal attitude between the therapist and the client (conf. e. g. Ludewig 1992, 2013). The formulation of a systemically substantiated therapeutic attitude had proven itself in practice. In the year 1987 I published a methodical framework composed of $10+1$ guidelines or questions for practical orientation of therapists (Ludewig 1987, 1992).

\section{Differentiations}

Systemic therapy had strongly differentiated itself in the 30 years since its establishment in many areas, and nothing else can be expected. This development cannot be understood in the end as a quite »natural « result of systemic thinking, the more so as this mode of thinking forgoes absolute truths and thus does not require and cannot expect any normative "adherence to principles". The most important movements in systemic therapy include, among others, the interventional approaches in the tradition of the Milan approach, short term therapy solution-oriented approaches according to de Shazer (e. g. 1988), cooperation-stressing approaches such as the Reflecting-Team according to Tom Andersen (1990), linguistically stressed approaches on the basis of so-called social constructionism according to K. J. Gergen (1991, 1999; Gergen \& Gergen 2004), of Goolishian \& Anderson (e. g. 1988), post-modern approaches (e. g. Anderson 1996, Anderson \& Gehart 2006, Hoffman 1990, 1993), narrative approaches based on anthropological and linguistic principles (e. g. White \& Epston 1989), biographical and 
encounter-oriented approaches (e. g. Welter-Enderlin \& Hildenbrand 1996) and diverse integrative approaches. A decisively personal and clear presentation of these developments is provided by Lynn Hoffman (2000). With all the differences in detail, these differentiations are characterised by sufficient commonalities to be recognised as being systemic. They share the meta-theoretical background of constructivist positions (including „social-constructivist“ and other non-realistic ones), and they mainly refer to theory with respect to the interdisciplinary programme of systemic sciences, meaning, the theories of self-organisation as well as the system and communication theories.

\section{Summary}

The systemic approach was classified by psychotherapy in the phenomenological domain of the social, in particular due to the fact that everything that takes place in therapy is communication. A significant advantage of the takeover of systemic thinking was relieving psychotherapy from its historically established exclusive embedding in analytical and objectivist thinking. Considering the fact that man can only be understood appropriately with the inclusion of the diverse systems that constitute them - biological, mental and social systems - psychotherapy should be understood as a comprehensive social exchange between similarly complex multi-system bio-psycho-social units, namely - people.

Considered systemically, people are living beings that live at the same time individually closed in themselves and embedded socially. Viewed this way, with the use of the systemic principle, an individual can neither be reduced to a homo biologicus nor to a homo sociologicus. The recursively generated relationship of the individual and the social does justice to the fact that being human is rooted in a social system, hence, it emerges at least in a pair. As a child of the concluding 20th century, systemic thinking allows us to simultaneously view this complex human existence simultaneously from biological, mental and social aspects, without having to reduce it to them. Beside its pragmatic efficacy, therein lies the main advantage of this mode of thinking for psychotherapy.

\section{Bibliography}

Ackerknecht, L. K. (1983): Individualpsychologische Familientherapie. Rückblick und gegenwärtige Praxis [in:] Schneider, K. (ed.): Familientherapie in der Sicht psychotherapeutischer Schulen. Paderborn (Junfermann). 
Andersen, T. (ed.) (1990): Das Reflektierende Team. Dortmund (modernes lernen).

Anderson H. (1996): Conversation Language and Possibilities: A Postmodern Approach to Therapy. New York (Basic Books).

Anderson, H. \& D. Gehart (eds.) (2006): Collaborative Therapy: Relationships and Conversations That Make a Difference. New York (Brunner-Routledge).

Anderson, H., H. A. Goolishian, G. Pulliam a. L. Winderman (1986): The Galveston Family Institute: Some Personal and Historical Perspectives [in:] D.E. Efron (ed.): Journeys. Expansion of the Strategic-Systemic Therapies. New York (Brunner/Mazel): 97-122.

Bateson, G., D. D. Jackson, J. Haley, J. H. Weakland (1956): Toward a Theory of Schizophrenia. Behavioral Science 1 (4): 251-264.

Bateson G. et al. (1969): Schizophrenie und Familie. Frankfurt (Suhrkamp)

Bateson G. (1972): Steps to an Ecology of Mind. A Revolutionary Approach to Man's Understanding of Himself. New York (Ballantine).

Cecchin, G. (1987): Hypothesizing, Circularity, and Neutraliy Revisited: An Invitation to Curiosity. Family Process 26, 405-413. [dt

Ciompi, L. (1997): Die emotionalen Grundlagen des Denkens. Entwurf einer fraktalen Affektlogik. Göttingen (Vandenhoeck \& Ruprecht).

Dell, P.F. (1982): Beyond Homeostasis: Toward a concept of coherence. Family Process 21: 21-41.

de Shazer, S. (1988): Clues. Investigating Solutions in Brief Therapy. New York (Norton).

Foerster, H. von (1985): Sicht und Einsicht. Braunschweig (Vieweg).

Foerster, H. von, B. Pörksen (1998): Wahrheit ist die Erfindung eines Lügners. Gespräche für Skeptiker. Heidelberg (Carl-Auer).

Gergen, K.J. (1991): The Saturated Self. New York (Basic Books).

Gergen, K.J. (1999): An Invitation to Social Construction. London (Sage).

Gergen, K.J., M. Gergen (2004): Social Construction: Entering the Dialogue. Chagrin Falls (Tao Institute Publ).

Glasersfeld, E. von (1987): Wissen, Sprache und Wirklichkeit. Braunschweig (Vieweg).

Goolishian, H. A. , H. Anderson (1988): Menschliche Systeme. Vor welche Probleme sie uns stellen und wie wir mit ihnen arbeiten [in:] Reiter, L., E. J. Brunner, S. Reiter-Theil (ed.): Von der Familientherapie zur systemischen Perspektive. Berlin (Springer), pp. 189-216.

Guntern, G. (1980): Die kopernikanische Revolution in der Psychotherapie: der Wandel vom psychoanalytischen zum systemischen Paradigma. Familiendynamik 5: 2-41.

Haley, J. (1976): Problem-Solving Therapy, San Francisco (Jossey-Bass).

Hoffman, L. (1981): Foundations of Family Therapy. New York (Basic Books)

Hoffman, L. (1990): Constructing Realities: An art of lenses. Family Process 29: 1-12.

Hoffman, L. (1993): Exchanging Voices: A Collaborative Approach to Family Therapy. London (Karnac).

Hoffman, L. (2000): Eine gemeinschaftsorientierte Perspektive de Therapie. Zeitschrift für systemische Therapie 18: 152.160 .

Jackson, D. D. (1981): The Question of Family Homeostasis. International Journal of Family Therapy 3: 5-15.

LeDoux, J. (2002): Synaptic Self. How Our Brains Become Who We Are. New York (Penguin).

Ludewig, K. (1987): 10 + 1 Leitsätze bzw. Leitfragen. Grundzüge einer systemisch begründeten Klinischen Theorie im psychosozialen Bereich. Zeitschrift für systemische Therapie 5: 178-191.

Ludewig, K. (1988): Welches Wissen soll Wissen sein? Reflexionen eines Praktikers zu Fragen einer systemischen Forschung. Zeitschrift für systemische Therapie 6: 122-127. 
Ludewig, K. (1992): Systemische Therapie. Grundlagen klinischer Theorie und Praxis. Stuttgart (Klett-Cotta), rev. 2015; (Polish 1995): Terapia systemowa. Podstawy teoretyczne i praktyka. Gdánsk (Gdańskie wydawnictwo psychologiczne).

Ludewig, K. (1999): »Überlebensdiagnostik« - eine systemische Option. Kontext 30 (2), 121-135.

Ludewig, K. (2005): Einführung die theoretischen Grundlagen der systemischen Therapie. Heidelberg (Carl-Auer) (an unpublished Polish translation exists at the Wielkopolskie Towarzystwo Terapii Systemowej WTTS, Poznań, Poland).

Ludewig, K. (2011): Psychische Systeme - ein nützliches Konzept für die systemische Praxis? Familiendynamik 36: 222-238.

Ludewig, K. (2013): Entwicklungen systemischer Therapie. Einblicke, Entzerrungen, Ausblicke. Heidelberg (Carl-Auer).

Luhmann, N. (1971): Moderne Systemtheorien als Form gesamtgesellschaftlicher Analyse. In: Habermas, J. and N. Luhmann: Theorie der Gesellschaft oder Sozialtechnologie - Was leistet die Systemforschung? Frankfurt a. M. (Suhrkamp), p. 7-24.

Luhmann, N. (1984): Soziale Systeme. Grundriss einer allgemeinen Theorie. Frankfurt (Suhrkamp).

Luhmann, N. (1995): Social Systems. Stanford University Press, Stanford California, United States.

Luhmann, N. (1997): Die Gesellschaft der Gesellschaft. Frankfurt (Suhrkamp).

MacGregor R, A. M. Ritchie, A.C. Serrano, F.P. Schuster, E.C. McDanald, H.A. Goolishian (1964): Multiple Impact Therapy with Families. New York (McGraw-Hill).

Maturana, H. R. ( 1976): Biology of language: The epistemology of reality [in:] Miller G. A., E. Lenneberg (eds.): Psychology and Biology of Language and Thought. New York (Academic Press).]

Maturana, H. R. (ed.) (1982): Erkennen: Die Organisation und Verkörperung von Wirklichkeit. Braunschweig (Vieweg).

Maturana, H. R. (1988): Reality: The search for objectivity or the quest for a compelling argument. Irish Journal of Psychology 9, 25-82.

Maturana, H. R. (1990): Biología de la Cognición y Epistemología. Temuco (Univ. de La Frontera)

Maturana, H. R, F. J. Varela (1972): De máquinas y seres vivos. Santiago de Chile (Editorial Universitaria); Engl. (1975), The Organization of the Living: A Theory of a Living Organization. International Journal of Man-Machine Studies 7: 313-332.

Maturana, H. Varela, F. J. (1980) Autopoeisis and Cognition. The Realization of the Living. Dordrecht, Holland/ Boston, United States/ London, UK. Reidel Publishing Co. Boston Studies in the Philosophy of science, 42 .

Maturana, H. R., F. J. Varela (1984): El árbol del conocimiento. Santiago (Editorial universitaria); Engl. (1987), The Tree of Knowledge. Biological Basis of Human Understanding. Boston (Shambhala Publ.).

Minuchin, S. (1974): Families and Family Therapy. Harvard (University Press).

Roth, G. (2001): Fühlen, Denken, Handeln. Wie das Gehirn unser Verhalten steuert. Frankfurt/ Main (Suhrkamp).

Selvini Palazzoli, M., L. Boscolo, G. Cecchin \& G. Prata (1975): Paradosso e controparadosso. Milano: Feltrinelli; Engl. (1978): Paradox and Counterparadox. New York (Aronson).

Stierlin, H. (1983): Familientherapie: Wissenschaft oder Kunst? Familiendynamik 8: 364-377.

Varela, F. J. (1979): Principles of Biological Autonomy. New York (Elsevier North Holland).

Varela, F. J., E. Thompson, E. Rosch (1991): The Embodied Mind. Cambridge/Mass. (MIT-Press).

Wahrig (1997): Deutsches Wörterbuch. Gütersloh (Bertelsmann), 6th ed. 
Watzlawick, P., J. H. Beavin, D. D. Jackson (1967): Pragmatics of Human Communication, New York (Norton).

Watzlawick, P., J. H. Weakland u. R. Fisch (1974): Change: Principles of Problem Formation and Problem Resolution. New York (Norton).

Welter-Enderlin, R., B. Hildenbrand (1996): Systemische Therapie als Begegnung. Stuttgart (Klett-Cotta).

White, M., D. Epston (1989): Literate Means to Therapeutic Ends. Adelaide (Dulwich Centre Publ).

Wynne, L. C., M. T. Singer (1965): Denkstörung und Familienbeziehung bei Schizophrenen. Parts I-IV. Psyche 19: 82-160. 
